\title{
Microfundamentos: Hyman P. Minsky e os modelos de fragilidade financeira
}

Marília Bassetti Marcato ${ }^{1}$

Resumo: Este artigo tem como objetivo apresentar a ponte de intermédio entre as esferas micro e macroeconômica, sob a perspectiva de Hyman P. Minsky, considerando sua Hipótese de Instabilidade Financeira. Dessa forma, foram analisados os aspectos microeconômicos que fundamentam as interações dinâmicas dos agentes. Para além da análise de suas obras, buscou-se expor algumas contribuições recentes, em especial os modelos de fragilidade financeira de Crotty e Goldstein e de Chiarella e Di Guilmi.

Palavras-Chave: Minsky, Hyman P., Instabilidade financeira, Microfundamentos.

Classificação JEL: B22; B59 


\title{
Microfoundations: Hyman P. Minsky and the financial fragility models
}

\begin{abstract}
This article aims to present the intermediate bridge between the micro and macroeconomic levels, from the perspective of Hyman P. Minsky, considering his Financial Instability Hypothesis. Thus, we analyzed the microeconomic aspects that underlie the dynamic interactions of agents. In addition to the analysis of his works, we sought to expose some recent contributions, in particular models of financial fragility of Crotty and Goldstein and Chiarella and Di Guilmi.
\end{abstract}

Key Words: Minsky, Hyman P., Financial instability, Microfoundations.

JEL Classification: B22; B59.

Introdução

As variáveis financeiras desempenham um papel fundamental na análise da dinâmica macroeconômica sob a perspectiva keynesiana recente. Segundo Fazzari et. al. (2000) um dos aspectos que define a macroeconomia keynesiana é que mudanças na demanda agregada causam flutuações no produto e no emprego. Tais flutuações normalmente tomam a forma de ciclos econômicos, ou seja, a trajetória do produto apresenta estágios bem definidos de recessão e crescimento. Segundo os autores, pouco é o esforço de pesquisa visto, dentro da perspectiva keynesiana, que se volta para entender o que gera um processo cíclico. Nesse sentido, o trabalho de Hyman P. Minsky é uma exceção.

A contribuição de Hyman P. Minsky para a compreensão dos determinantes financeiros da instabilidade do investimento é inegável. O autor optara por não desenvolver modelos matemáticos para embasar suas hipóteses e nesse sentido, um imenso progresso tem sido verificado. Além disso, pode-se dizer que não se encontra uma preocupação explícita em suas principais obras em fundamentar seus pressupostos sob alicerces microeconômicos. Segundo Crotty e Goldstein (1992), diversos autores têm concentrado seus esforços na criação de modelos que tratem dos ciclos abordados por Minsky e incorporem as interações entre as variáveis financeiras e de investimento ao nível macroeconômico ou de equilíbrio geral.

Segundo Fazzari et. al (2000), a teoria de Minsky enfatiza o financiamento 
do investimento através da geração interna de fluxo de caixa ${ }^{1}$ e de dívidas ${ }^{2}$. Apesar das expectativas apresentarem um papel fundamental tanto na teoria de Keynes, quanto na de Minsky, não se verifica um grau de formalização suficiente.

O grau de fragilidade sistêmica envolve uma análise ao nível microeconômico. Segundo Taylor e O'Connell (1985), uma das possíveis razões pela qual o trabalho de Minsky tenha sido tão negligenciado é sua completa ausência de formalidade quanto às questões algébricas. No entanto, segundo Chiarella e Di Guilmi (2011) esse não é mais o caso ${ }^{3}$, já que, recentemente, uma gama de pesquisadores tem buscado associar as questões de microfundamento da macroeconomia a agentes heterogêneos e em evolução. Nesse sentido, diversos são os trabalhos que buscam elaborar modelos com um fundamento microeconômico satisfatório.

A relevância dos aspectos microeconômicos em um modelo minskyano não pode ser meramente associada a uma tentativa de maior adequação aos padrões mainstream. Segundo Chiarella e Di Guilmi (2012), essa questão é tão central que toda interpretação de Minsky acerca de Keynes "can be summarized as a theory of the determination of the effective budget constraints. The economics of the determination of the budget constraint logically precedes and sets the stage for the economics of the selection of particular items of investment and consumption." (Minsky, 2008, p.129, apud Chiarella e Di Guilmi, 2012, p.6)

Este trabalho aborda a base microeconômica minskyana. A quase inexistência de uma matematização formal de suas proposições acaba por elevar o grau de dificuldade em expor de maneira detalhada e coerente os aspectos microeconômicos de sua contribuição. Nesse sentido, buscou-se apresentar os principais microfundamentos presentes na teoria financeira a respeito dos ciclos de investimento de Minsky. Além disso, a ausência de um rigor matemático satisfatório, independente da relativização entre os benefícios e malefícios dessa ausência, acaba por dar margem à contribuição posterior de diversos autores. Nesse sentido, como será visto adiante, um enorme progresso pode ser verificado especificamente valendo-se dos pressupostos de Minsky.

Antes de uma exposição acerca de alguns trabalhos recentes que empreendem o esforço citado acima, cabe uma breve apresentação do contexto geral do qual provêm tais esforços. Ou seja, apresentar o quadro geral, revisitando algumas obras de Minsky e algumas análises das mesmas, faz-se necessário. Destaque para sua emérita obra de 1986 - Stabilizing an Unstable Economy,

1 Segundo os autores, o fluxo de caixa como uma fonte interna de recursos apresenta um custo de oportunidade menor para a firma se comparado à geração de dívidas.

2 O fluxo de novos financiamentos via dívida seria um múltiplo do fluxo de caixa, sendo que o tamanho do multiplicador dependeria das dívidas correntes e das expectativas em relação à economia. 3 Segundo os autores, Masanao Aoki (1996, 2002) merece destaque ao proporcionar uma contribuição relevante, permitindo o desenvolvimento analítico da teoria de Minsky, incorporando fundamentos microeconômicos essenciais. 
ressaltando a Hipótese de Instabilidade Financeira ${ }^{4}$; as análises de sua tese de doutorado, Induced Investment and Business Cycles, e de sua obra de 1975 - John Maynard Keynes.

A estrutura deste artigo encontra-se dividida da seguinte forma: além desta introdução; o primeiro item apresenta a construção de um quadro geral, composto pelas contribuições do próprio Hyman P. Minsky, tendo em vista a Hipótese de Instabilidade Financeira e dos elementos microeconômicos de algumas de suas obras, conforme as análises de Jan Toporowski, Thomas Palley e James Crotty; o segundo item apresenta a evolução dos microfundamentos minskyanos, em específico o modelo de Crotty e Goldstein e o modelo de Chiarella e Di Guilmi; e o terceiro item apresenta a conclusão deste trabalho.

\section{O quadro geral}

\subsection{Hyman P. Minsky e a análise de fragilidade financeira: a Hipótese de Instabilidade Financeira}

"As boas teorias são abstrações pertinentes, e a pertinência se altera quando a história evolui” (Chick,1983,p.3)

Hyman P. Minsky compõe uma geração de economistas que viveram o impacto da Grande Depressão sobre sua formação acadêmica. E como elucidado na paráfrase de Victoria Chick, o ambiente econômico e as especificidades históricas certamente explicam o mérito da contribuição e pertinência de determinada teoria econômica que se sobrepõe ao tempo. Assim, as formulações de Minsky se sustentarem em um ambiente de economia fechada não o torna menos expressivo. Tal conveniência era comum à maioria dos economistas da época e, além disso, o ambiente econômico em que viviam favorecia tal abordagem. O cenário econômico era marcado pela estabilidade das transações internacionais oriunda do acordo de Bretton Woods e pelo relativo fechamento da economia estadunidense, além do fato dessa dispor da posição do dólar como moeda internacional.

Diante de suas diversas contribuições, um elemento central de seu legado é a Hipótese de Instabilidade Financeira (HIF). Essa sofrera significativa variação 5 ao longo do tempo e tem como principais proposições, segundo o próprio Minsky (1994): 1) Uma economia capitalista que opere sem restrições e que

\footnotetext{
4 Há, entretanto, o desprendimento em não aprofundar a análise quanto à dinâmica dos agentes e o papel das instituições, além da percepção de que há ainda diversos aspectos da contribuição de Minsky que não devem ser ignorados.

5 Para maiores detalhes acerca da historicidade da Hipótese de Instabilidade Financeira, ver Lourenço (2006).
} 
possua um sistema financeiro sofisticado, complexo e em contínua evolução - a economia de "Wall Street"- alterna períodos de estabilidade e períodos de turbulência (mesmo que a situação inicial seja de estabilidade); 2) Tais comportamentos econômicos são endógenos às economias capitalistas; 3) A turbulência pode assumir a forma de bolhas especulativas, inflações interativas ou profundas deflações de débitos inter-relacionadas; 4) Tais formas apresentam-se com movimento próprio e serão findadas por uma série de restrições - sejam realizadas por instituições ou práticas, por intervenções políticas que afetem a estrutura institucional ou por propriedades de auto-organização dos mercados, de tal forma que se conduz à estabilidade; 5) Provavelmente, o período que se segue é marcado por baixos níveis de atividade econômica; 6) A expansão toma forma novamente, dada a busca por interesses próprios dos agentes econômicos, levando à especulação e à baixa inflação.

A instabilidade seria inerente ao sistema capitalista, não estando relacionada apenas a choques externos ${ }^{6}$ ou a possíveis políticas conduzidas erroneamente. Tal incerteza tenderia a se ampliar, sendo papel das instituições e da política econômica redirecionar a instabilidade à estabilidade.

Os principais aspectos da $\mathrm{HIF}^{7} \mathrm{se}$ fundamentam tanto sobre aspectos empíricos, quanto teóricos. Nesse sentido, empiricamente, observa-se a ocorrência na economia capitalista de períodos de inflação e deflação de ativos e débitos, que podem ter seus efeitos ampliados, dada a reação da economia.

Já no campo teórico, o caminho que se constrói de uma situação econômica robusta para outra de completa fragilidade inicia-se com um período substancial de ausência de dificuldades financeiras sérias. Esse período, por sua vez, conduz à formação de uma economia eufórica, na qual o aumento do financiamento de curto prazo de posições de longo prazo torna-se uma ação rotineira. Ou seja, as estruturas de passivos desejadas pelas unidades econômicas que atuam como intermediários financeiros alteram-se, dada a euforia econômica. Para Minsky (1986), esses momentos de euforia constituem uma parte do processo endógeno multifacetado. Nesse sentido, não se pode dissociar o passado do presente ou do futuro, pois essas esferas estão interligadas não apenas pelas características dos bens de capital e da força de trabalho, mas também pelas relações financeiras.

Segundo Minsky (1986), os esforços no sentido de práticas financeiras inovadoras seriam uma das raízes da instabilidade financeira inerente ao capitalismo. Tal dinâmica tem como origem as atividades de profit-seeking realizadas pelas famílias, pelas empresas e pelos bancos. Esses últimos, especificamente, irão buscar novas formas de aumentar o retorno de seus ativos ou de reduzir

6 Minsky considera a possibilidade do fato catalisador de uma crise financeira ser um "evento externo", porém, como será exposto adiante, tal evento não estaria nos moldes do que, segundo a teoria neoclássica, se faria um choque exógeno. Além disso, Minsky reforça que a razão pela qual um "choque" possui o poder de alterar o status quo da economia é energicamente endógena.

7 Minsky (1992). 
o custo de seus passivos, contando com novos instrumentos, novas espécies de contratos e novas instituições. Daí, tem-se o afrouxamento da articulação entre as políticas do Banco Central e o volume de financiamento disponível, dada as inovações para se captar recursos. Como resultado, as autoridades econômicas em busca de resultados tendem a cometer excessos, trazendo a economia para um estado cada vez mais próximo de uma crise financeira. Cada inovação financeira teria como consequência o financiamento de uma demanda adicional por capital e por ativos financeiros, conduzindo a níveis maiores de investimento. Dessa forma, tem-se um aumento no preço dos ativos, o que, por sua vez, aumentaria o preço de demanda por investimento atual e aumentaria o financiamento disponível para investimento.

Porém, não se trata apenas da tendência em inovar endogenamente, mas também dos ganhos potenciais. Tais ganhos aumentam endogenamente, na forma de oportunidades de arbitragem, gerados por um estado financeiro saudável. Esse aumento, segundo a interpretação de Arestis e Glickman (1999), pode ser visto sob três formas:

(a) 'in an economy with a robust financial structure, short-term interest rates (...) will be significantly lower than the yield from owning capital.'(1986, p.211); (b) 'interest and principal payments on longerterm private debts, which are synchronized to their pay-outs on quasirents that capital assets are expected to yield, will be low relative to these quasi-rents' (ibid.); and (c) 'the interest rate on short-term money-like liabilities of firms and financial institutions will be lower than on the longer-term liabilities used in hedge-financing positions in capital assets'(ibid). (Arestis e Glickman, 1999, p. 6)

Além disso, reforça-se a ideia de que não se trata apenas de incentivos a alterar o portfólio das empresas, mas também das famílias e das instituições financeiras, inclusive o governo e as unidades internacionais. Arestis e Glickman (1999) apontam ainda para a noção de que não seria simplesmente devido à mudança na fonte de financiamento das firmas para uma forma de débito de longo-prazo que caracterizaria essas como uma unidade de financiamento especulativa. No entanto, uma unidade que empresta no curto prazo para financiar a aquisição de ativos no longo prazo seria financeiramente especulativa em ambos os sentidos distinguidos por Minsky. E seria esse o fator primário que injetaria fragilidade para a estrutura financeira, caracterizando-se como um "fenômeno endógeno". Sob o referencial keynesiano, o autor reforça a ideia de que a especulação domina a unidade, de tal forma que as preferências agora buscam ganhos financeiros imediatos, em detrimento dos ganhos financeiros de menor risco e de maior prazo.

Para Minsky (1986), o determinante central do comportamento do sistema 
financeiro seria o nível de lucro. Valendo-se da visão de Kalecki e Levy, na qual o lucro seria determinado pela estrutura de demanda agregada, em uma estrutura mais complexa, o lucro agregado seria igual ao investimento agregado somado aos gastos do governo. Assim, as expectativas de lucro estão interconectadas ao nível de investimento futuro e os lucros realizados seriam um subproduto do investimento corrente. A situação das obrigações financeiras, portanto, dependerá do nível de investimento.

Nesse sentido, Hyman P. Minsky utiliza uma taxonomia própria para caracterizar como as obrigações financeiras estão relacionadas à instabilidade financeira, realçando o papel dos fluxos de caixa das unidades financeiras e os compromissos de pagamentos do endividamento. Se os fluxos de renda, que seriam os salários e os pagamentos de produtos intermediários e finais, fazem-se suficientes para cumprir com todas as obrigações, a unidade será denominada hedge. Se as receitas dos rendimentos forem menores que os fluxos de passivos, haverá a necessidade de postergar o pagamento da dívida - seria a unidade especulativa. Já havendo a necessidade de aumentar o endividamento, tem-se a unidade Ponzi. É preciso observar que as unidades especulativas e Ponzi dependem das condições do mercado financeiro para honrar as suas dívidas, utilizando-se de transações de portfólio para tanto. Já uma unidade hedge pode se transformar em especulativa, caso haja uma insuficiência da renda.

Dito de outra forma, um sistema financeiro será considerado frágil ou não de acordo com o tamanho e a força das margens de segurança ${ }^{8}$ e da probabilidade de ampliação das turbulências iniciais. Segundo Summa (2005), a "instabilidade financeira" seria decorrente da deterioração dos balanços das diversas unidades financeiras em momentos de boom. Ou seja, aparece quando a economia torna-se financeiramente mais frágil durante a expansão econômica. E essa definição, extremamente geral, tem como ponto positivo a possibilidade de incorporar diversos fenômenos, inclusive, fatores decorrentes da abertura da economia.

A combinação das três unidades financeiras diz muito sobre a condição de estabilidade de determinada economia. A dominação da posição hedge faz com que o padrão da taxa de juros permita a elevação do lucro via especulação. Dessa forma, há um aumento na demanda por ativos, elevando seus preços e possibilitando ganhos de capital. Forma-se um ambiente com ganhos de capital possíveis e esperados, ou seja, um ambiente compatível com o aumento das posições especulativa e Ponzi. Assim, as possibilidades de lucro, dada uma estrutura financeira saudável, levam tal estrutura à fragilidade de

8 A margem de segurança, segundo Kregel (1998), é um conceito que Minsky tomara emprestado de Benjamin Graham. Essa seria uma proporção que torna a unidade capaz de absorver mudanças não previstas nas entradas e saídas de capital. Ou seja, a capacidade de gerar lucros acima das necessidades de pagamentos de juros e de reembolso do principal. 
forma puramente endógena ${ }^{9}$. Essa ideia pode ser vista em:

(I)n a world of uncertainty, given capital assets with a long gestation period, (...) the successful functioning of an economy within an initially robust financial structure will lead to a structure that becomes more fragile as time elapses. Endogenous forces make a situation dominated by hedge finance unstable (...). (Minsky 1986, p.213)

Um sistema financeiro frágil pode ter seu funcionamento interrompido por alguns eventos não necessariamente incomuns. Segundo Minsky (1986), essa quebra no funcionamento regular da economia apresenta-se sempre que há alguma alteração nas relações de valor-presente. Normalmente, isso ocorre após o aumento na demanda financiada por capital especulativo elevar sua taxa de juros, os salários da força de trabalho e o preço dos materiais utilizados, de tal forma que as margens de lucro e, então, a habilidade de validar o passado são erodidas.

Esses eventos citados são endógenos ao processo. Dito de outra forma, e como destacado por Kregel (1998), mudanças nas variáveis macroeconômicas podem levar a alterações nas posições financeiras. Por exemplo, uma mudança na política monetária doméstica que cause aumento na taxa de juros possui dois efeitos sobre os projetos financeiros alavancados - primeiro, há uma queda no valor presente dos fluxos de capital que se espera realizar, dado os projetos financeiros; segundo, há um aumento no fluxo de caixa comprometido com as taxas de financiamento quando o empréstimo é primariamente de curto prazo ou de base ajustável. Porém, segundo Arestis e Glickman (1999), Minsky também alerta para a possibilidade de serem eventos externos, ainda que sob uma ótica oposta à ideia neoclássica de choque exógeno, os responsáveis pela interrupção da estabilidade ${ }^{10}$.

O desenvolvimento de um novo ambiente institucional coloca em questão até que ponto a HIF, sob sua forma tradicional, seria ainda capaz de analisar a dinâmica financeira. ${ }^{11} \mathrm{O}$ efeito do saldo de transações correntes, via lucro empresarial, por exemplo, fora um ponto incorporado à sua análise. No entanto, não restam dúvidas que os esforços de Minsky no sentido de incorporar alguns aspectos de economias abertas não foram satisfatórios. Hyman P. Minsky faleceu em 1996, antes de incorporar outros diversos aspectos relevantes ao novo ambiente econômico, deixando em aberto, inclusive, questões como a formalização dos microfundamentos de sua análise.

9 Dado o caráter endógeno da instabilidade na economia, haveria alguns mecanismos que evitariam que as depressões fossem recorrentes. Esses mecanismos, o Big Bank e o Big Government, podem ser analisados em Minsky (1957), Minsky (1982) e Minsky (1986).

10 Para maiores detalhes acerca das possíveis interações presentes na interpretação de Minsky sobre as crises financeiras, ver o modelo desenvolvido por Taylor e O'connell (1985).

11 Segundo Arestis e Glickman (1999), um fato que possa ter contribuído para a não utilização da base minskyana na análise da crise do sudeste asiático é o modelo de Minsky ser embasado em uma economia fechada, contrastando as economias abertas dos países do sudeste asiático. 


\subsection{Os microfundamentos de Hyman Minsky: as análises de Toporowski, Palley e Crotty}

Hyman P. Minsky escrevera sua tese de doutorado, Induced Investment and Business Cycles, sob a orientação de Joseph Schumpeter e posteriormente de Wassily Leontief. Diferente do que se pode esperar de um autor cuja notoriedade se deu, dentre outros, pela pesquisa acerca da fragilidade financeira do sistema capitalista, Minsky constrói uma série de reflexões tendo como base a microeconomia e os aspectos metodológicos da ciência econômica. Apesar dos aspectos microeconômicos de sua obra serem pouco explorados, Toporowski (2006) retoma as construções de Minsky em sua tese, considerando a maior parte do trabalho desenvolvido em Harvard como um exame prolongado das consequências dos passivos financeiros sobre o comportamento do investimento das firmas.

Segundo Toporowski (2006), o tratamento dado ao monopólio por Minsky é digno de destaque, dada sua rejeição à análise de concorrência imperfeita que emergira dos trabalhos de Chamrberlin e Joan Robinson, por volta de 1930. Segundo Minsky, essas teorias seriam dignas de crítica por manterem o pressuposto tradicional das firmas em concorrência perfeita maximizarem seus lucros. Além disso, a adoção de tal pressuposto lhe parecia um meio de alcançar equações tratáveis, simplificando a análise.

Minsky remonta a um conjunto de ideias que compõem a noção de "monopólio condicional", formulado por Alfred Marshall em seu livro Industry and Trade, mostrando-se extremamente seletivo quanto ao uso do trabalho de Marshall.

Marshall had recognized that, apart from natural or legal monopolies (such as land-ownership), firms with a dominant position in their respective markets do not usually plunder their customers for the maximum profit that they can secure, if only because such high profits will attract other firms into the market. (Toporowski, 2006, p.9)

Ou seja, os monopólios se mantêm nesta condição estabelecendo preços baixos o suficiente para desencorajarem qualquer competição potencial. Daí, caminha-se para uma discussão acerca de como as firmas sobrevivem sob diferentes condições de financiamento e de mercado e sob a ameaça de vulnerabilidade a uma queda na demanda por seus produtos ou um aumento da concorrência. Segundo Toporowski (2006), a originalidade de Minsky está na forma como o autor incorporou os custos de financiamento em várias curvas de custo, para que o tradicional aparato marshalliano de curvas de custo de curto, médio e longo prazo se torne mais complexo, considerando os financiamentos que as firmas devem fazer para realizar investimentos. Introduz-se, então, a noção da firma como um balanço de ativos e passivos em oposição à noção da firma como um empresário tomando decisões em relação à produção. 
Haveria, então, uma inconsistência no trabalho de Minsky aparente apenas no seu trabalho de doutorado. Segundo Toporowski (2006), ao mesmo tempo em que adotar o princípio da maximização do lucro quanto ao comportamento da firma seria errado por poder confundir a economia positiva com a normativa, sugerir que as curvas de custo e receitas possam ser obtidas ao imputar dados do balanço em plantas de custo e receitas é ilógico, pois pressupõe que decisões independentes estão sendo feitas ao nível da planta.

Ao investigar os mecanismos de transmissão da esfera financeira para o investimento, a abordagem da Teoria de investimento " $q$ " dá relevância aos aspectos financeiros, dando ao mercado de ações um importante papel no processo de acumulação de capital. Palley (1999) sugere uma distinção entre a teoria do " $q$ " real e a teoria do " $q$ " financeiro. Nesse sentido, Minsky $(2008,1986)$ pode ser associado a uma versão fraca de “q", na qual o mercado de ações afeta o custo do capital, mas não fornece sinais coerentes acerca da eficiência marginal do capital.

A determinação do investimento, nos termos de Minsky, se dá a partir da seguinte comparação:

The theoretical argument of how investment is determined involves a comparison of the [demand] price of capital assets and [the supply price] of investment output. In a corporate capitalist economy with a stock exchange, the market's valuation of a firm's capital assets and market position substitutes for the [demand] price) of capital assets. (Minsky,1986, p. 186, apud Palley, 1999, p.8)

Minsky (1986) acredita que a determinação de preços no mercado financeiro não poderia ser explicada por uma teoria do valor essencial ${ }^{12}$ das firmas, mas sim pela analogia do "concurso de beleza" de Keynes. Tal ideia é apresentada, no capítulo 12, em sua Teoria Geral do Emprego, do Juro e da Moeda, no qual Keynes faz uma comparação entre o comportamento dos participantes de um concurso de beleza com o comportamento do mercado financeiro.

Para variar um pouco de metáfora, o investimento por parte de profissionais pode ser comparado aos concursos organizados pelos jornais, onde os participantes têm de escolher os seis rostos mais belos entre uma centena de fotografias, ganhando o prêmio o competidor cuja seleção corresponda, mais proximamente, à media das preferências dos competidores em conjunto; assim, cada concorrente deverá escolher não os rostos que ele próprio considere mais bonitos, mas os que lhe parecem mais próprios a reunir as preferências dos outros concorrentes, os quais encaram o problema do mesmo ponto de vista.[...] Alcançamos o terceiro grau, no qual empregamos a nossa inteligência em antecipar o que a opinião geral espera que seja a opinião geral. E há

12 Este valor "fundamental" seria o valor presente esperado descontado os fluxos de lucro atual e futuro da firma. Segundo essa interpretação, as expectativas quanto aos lucros futuros seriam convertidas a um equivalente valor presente. 
pessoas, segundo creio, que vão até o quarto e o quinto grau, ou mais longe ainda. (Keynes, 1936, p.129)

Tal comportamento dá margem à possibilidade de ondas de especulação e de pessimismo, o que poderia alterar o equilíbrio dos preços.

Palley (1999) estabelece uma comparação entre o $q$ de Brainard e Tobin (1968, 1977) e o $q$ de Minsky, indicando que tais autores compartilham a mesma visão acerca do mecanismo de transmissão $q$ ao acreditar que o equilíbrio dos preços possui relevância para a determinação do investimento. Entretanto, há de se fazer uma ressalva. Tais autores possuem diferentes visões acerca da racionalidade do mercado de ações como regulador da acumulação de capital.

Both believe that equity prices value the existing capital stock, and both believe equity prices impact the "incentive" to invest through a cost of capital channel. They differ regarding the equity valuation process. (Palley, 1999, p.9)

Como já dito, Minsky adota o conceito do concurso de beleza de Keynes. Nesse sentido, a significância do bem-estar social dos sinais econômicos providos pelo mercado financeiro que seria a maior preocupação, e não a lógica causal do $q$ em si. Tais sinais podem ser contaminados pela especulação e, dada a lógica do concurso de beleza, eles não conteriam nenhuma informação acerca da eficiência marginal do capital.

Ao tentar compreender por que diversos pós-keynesianos de renome desenvolveram teorias de investimento baseadas em uma única causa a respeito da origem da instabilidade macroeconômica ${ }^{13}$, Crotty (1990) critica a obra de Minsky. Segundo o autor, assim como Keynes (1936), em seu décimo - segundo capítulo, Minsky vê a origem da instabilidade apenas no setor financeiro. Além disso, o autor se aproximaria da interpretação de Tobin ao considerar os proprietários e os gerentes como agentes econômicos idênticos. Enquanto, na verdade, haveria uma hierarquia na qual o proprietário apresenta-se no topo e o gerente como subserviente. Já que os primeiros seriam os iniciadores das decisões econômicas, enquanto os segundos seriam apenas os agentes passivos da decisão ao cumprir ordens ${ }^{14}$.

Crotty (1990) apresenta um Minsky ainda cru quanto à sua teoria dos determinantes do lucro em John Maynard Keynes. Para o autor, algumas relações de determinação fundamentais, tais como as relacionadas à taxa de juros, não foram trabalhadas. Já em Minsky (1986) vê-se a adoção da teoria do lucro de Michal Kalecki, na qual os investimentos gerariam renda enquanto os mecanismos de preço determinam simultaneamente a parcela de lucro e a porcentagem da renda que é poupada. Sob a visão de Kalecki, o exógeno "grau 
de monopólio" determina o markup que as empresas aplicam para determinar preços, o que por sua vez determina a parcela de lucro. O lucro dos capitalistas seria determinado propriamente pelos investimentos. Além disso, há uma relação causal unilateral na qual os gastos autônomos dos capitalistas em investimentos criam automaticamente o seu próprio financiamento no modo de uma poupança de igual valor. A poupança não financiaria investimento, não havendo uma poupança ex-ante, já que essa seria um fluxo de rendimentos simultâneo ao investimento. Cada nível de investimento é autossustentado. Nas palavras de Crotty (1990):

Moreover, the assumed constancy of the markup and profit share guarantees that the rate of profit on investment is likewise constant, no matter what the level of investment. This means that the high rate of investment of the boom can never initiate a chain of real-sector developments [...] that lower the rate of profit, and therefore cause a decline in the rate of investment, production, and employment. There are no real-sector mechanisms that can disrupt the pace of investment spending. (Crotty, 199o, p.11)

Minsky (1986) enfatiza a não determinação mútua de investimento e lucro. Seria preciso primeiramente uma queda no investimento para se induzir uma queda subsequente nos lucros. Seguindo tal lógica, Minsky é incapaz de observar no setor real da economia um impedimento ao crescimento estável, o que, segundo Crotty (1990), constitui sua limitação em observar que as origens da instabilidade estão no mercado financeiro.

\section{Microfundamentos e a construção de modelos de fragilidade financeira}

\subsection{O modelo de Crotty e Goldstein}

No que diz respeito à evolução dos fundamentos microeconômicos da teoria de Minsky, segundo Crotty e Goldstein (1992), uma das razões para esse desalinhamento do progresso teórico ao nível microeconômico seria a adoção por Minsky da “Teoria q-Tobin”. Outra possível razão é que as suposições centrais da teoria keynesiana, tais como que o futuro seria uma incógnita e que o investimento se faz substancialmente irreversível, dificultam a formalização teórica. Crotty e Goldstein (1992) avançaram na construção de uma teoria acerca da decisão de investir que incorporasse tais dimensões da teoria keynesiana.

Diferente de Keynes, que considerava as diferenças qualitativas entre os acionistas e os gerentes da empresa, Minsky aceita o aspecto da Teoria q-Tobin que considera proprietários e gerentes como agentes econômicos idênticos, 
não havendo qualquer independência no processo de decisão da firma. Crotty e Goldstein (1992) criaram um modelo que poderia ser utilizado para sustentar a teoria de Minsky acerca da instabilidade do investimento. Os autores irão seguir a abordagem de Keynes, já que essa seria, segundo eles, mais consistente com o espírito do modelo de Minsky, já que o mesmo rejeita as considerações neoclássicas a respeito da incerteza. Nesse sentido, seria lógico considerar a existência de informação assimétrica.

De maneira geral, Crotty e Goldstein (1992) consideram primeiramente que a firma maximiza uma função de preferência $O(G, S)^{15}$, na qual " $G$ " corresponderia aos objetivos de "growth-profit" da empresa e "S"16 seria a preocupação gerencial acerca da segurança financeira da firma, e então, pela sua própria autonomia de decisão, ou seja, seria o objetivo de "security-autonomy" financeira. Nesse sentido, ambas as variáveis seriam funções da trajetória do estoque de capital pelo horizonte de planejamento de longo prazo dos gerentes das empresas.

Ao considerar o investimento como irreversível, sob outra perspectiva vê-se que os compromissos financeiros também se fazem irreversíveis. Assim, com expectativas frustradas, os gerentes vivem uma ameaça a sua autonomia de decisão, sendo que se seus compromissos com os credores não forem cumpridos, poder-se-ia chegar à falência da empresa. A incerteza quanto ao futuro torna a acumulação, enquanto necessária para alcançar o crescimento, simultaneamente perigosa para os gerentes.

No modelo desenvolvido, o investimento é afetado por três aglomerados de variáveis distintos - variáveis que refletem atitudes gerenciais subjetivas, que refletiriam o otimismo dos gerentes em relação ao crescimento futuro do mercado e a confiança desses em sua habilidade em prever significativamente; variáveis que descrevem o status financeiro da firma, tais como o estoque de débito inicial, a liquidez de seus ativos e a taxa de juros; e a margem de lucro determinada pelo setor real da economia. Segundo os autores, considerando a restrição de espaço, a discussão a respeito do papel do modelo no ciclo de Minsky limitou-se ao comportamento do investimento no momento final da expansão do ciclo ("onset-of-crises stage"). Porém, o modelo desenvolvido poderia ainda ser reproduzido em outras fases do ciclo econômico de Minsky e o grupo de determinantes do investimento seria rico o suficiente para explicar os ciclos econômicos sob diferentes padrões.

Assim, caminhou-se para um maior aprimoramento dos aspectos microeconômicos da teoria financeira de Minsky acerca dos ciclos de investimento, incorporando variáveis financeiras e subjetivas. 


\subsection{O modelo de Chiarella e Di Guilmi}

Chiarella e Di Guilmi (2011) utilizaram duas abordagens diferentes no seu estudo da macrodinâmica. A primeira seria baseada no agente, considerando um alto grau de heterogeneidade, e a segunda, seria uma aproximação estocástica, formulada a partir das ferramentas de agregação de Masanao Aoki.

Segundo Chirella e Di Guilmi (2011), Aoki (1996, 2002) utiliza ferramentas analíticas originalmente desenvolvidas em mecanismos estatísticos. Sob a perspectiva de Aoki, não se poderia saber exatamente qual agente, dado o grande número de agentes diferentes, encontra-se em qual situação ou se tal agente irá mudar sua condição. Mas, seria possível saber a possibilidade presente para uma dada situação. A ideia básica seria introduzir um nível mediano de agregação, agrupando os agentes em clusters de acordo com uma variável passível de medida. Seria, então, a dinâmica do número de firmas em cada cluster o que definiria a evolução de toda economia, a qual é identificável ao se especificar algumas considerações gerais acerca da evolução estocástica dessas quantidades.

Os autores buscaram criar um modelo de fragilidade financeira, segundo os termos de Minsky (2008) e Taylor e O'Connell (1985), contando com firmas que interagem entre si e são heterogêneas. Primeiro utilizou-se uma simulação numérica do agent model e então se comparou tal solução com a obtida pela técnica de agregação dinâmica estocástica. Nesses termos, observaram que seria possível formular uma análise mais profunda dos mecanismos de transmissão dos choques do setor financeiro para a economia real.

Para os autores, um dos pontos de contradição do trabalho original de Minsky seria a presença de firmas heterogêneas e a desconsideração de um nível de detalhamento microeconômico maior. Diferente do que pode ser visto nos originais, os autores irão afirmar que as equações expressas fazem referência ao nível microeconômico das firmas heterogêneas. Outra mudança no modelo proposto é considerar que a valoração dos ativos financeiros vem do mercado de ações, no qual os investidores apresentam expectativas heterogêneas a respeito dos futuros lucros da firma. Tais expectativas estariam conectadas à estratégia dominante do mercado de ações. E uma terceira alteração diz respeito à criação de um modelo que conectara o "endogenous money" ao montante total de ativos financeiros, não o tratando como um múltiplo da base monetária, como usualmente é feito na literatura. Na visão dos autores, este tratamento seria mais consistente com as ideias de Minsky.

Com relação às hipóteses comportamentais, Chiarella e Di Guilmi (2011) modelam a demanda por ativos líquidos de forma semelhante à apresentada por Minsky (2008). Ou seja, seriam os motivos keynesianos usuais para a preferência à liquidez (transação, precaução e especulativo). Assume-se que os agentes financeiros agem de acordo com um paradigma de racionalidade limitada, classificando-os de acordo com duas categorias - os grafistas e os 
fundamentalistas. Pode-se dizer que um fundamentalista, em média, irá focar seus investimentos em firmas hedges, enquanto os grafistas talvez prefiram ações mais arriscadas. Variações na proporção dos tipos de operadores não são dependentes do desempenho da firma e são simplesmente governadas por uma lei estocástica.

O modelo desenvolvido, então, ao considerar o caráter heterogêneo das firmas, em relação ao tamanho e às condições financeiras, acaba por gerar duas dinâmicas. Enquanto uma é uma aproximação estocástica que pode ser resolvida analiticamente, a outra é baseada no agente e permite uma solução numérica que replica alguns fatos estilizados da economia real.

Segundo Chiarella e Di Guilmi (2011), algumas considerações formuladas no nível microeconômico foram fundamentais para o embasamento do modelo proposto. Tais são:

a) Considera-se a presença de informação imperfeita nos mercados de capital. Assim, as firmas preferem financiar seus investimentos com seus próprios lucros retidos, e apenas no caso desses não serem suficientes, busca-se, então, a emissão de novas dívidas.

b) As firmas são classificadas em dois grupos, agrupando no mesmo grupo as firmas especulativas e Ponzis. Define-se, então, como especulativa (grupo 1) as firmas que precisam financiar seus investimentos com dívidas e como hedge (grupo 2) as firmas que conseguem financiar todo seu investimento com lucros retidos. ${ }^{17}$

c) A cada período a firma tem como meta um investimento específico. O novo nível de capital determinará, então, a demanda por trabalho e produto. O investimento é decidido tendo como base o "shadow price" 18 do capital, no qual o parâmetro "a" mede a sensibilidade das firmas em relação ao valor corrente dos ativos.

d) As firmas produzem um bem que pode ser utilizado tanto para seu consumo quanto para seu investimento. O preço final é obtido aplicando-se um mark-up $(\mathrm{u})$ ao custo direto de produção: $\mathrm{P}(\mathrm{t})=(1+\mathrm{u}) \mathrm{w}(\mathrm{t}) \mathrm{b}$. Tais quantidades seriam iguais para todas as firmas.

e) Todos os salários são consumidos e a unidade salarial varia em cada período para garantir o equilíbrio no mercado do produto.

f) O montante de trabalho necessário é residualmente determinado, uma vez que o nível ótimo de investimento, e então de capital, é quantificado, dado que as firmas utilizam tecnologias com coeficientes constantes. A oferta de trabalho é infinitamente elástica.

g) As firmas financiam a parte do investimento que elas não conseguem

17 Essa classificação será a base da solução analítica proposta pelo modelo.

$18 \mathrm{I}^{j}(t)=a P K^{j}(t)$ 
cobrir com seus recursos próprios. Portanto, a dependência em relação à taxa de juros reflete o fato de que em períodos com uma alta taxa de juros preferem-se ações.

h) O cronograma de todo o processo apresenta-se da seguinte forma: no primeiro estágio as expectativas do mercado determinam o "shadow price" do capital e o nível de investimento desejado. No próximo período, as firmas implementam a decisão, produzindo o bem final. $\mathrm{O}$ produto é, então, vendido no período seguinte.

i) A probabilidade de uma nova firma entrar é diretamente proporcional a variação na produção agregada, em relação ao período anterior.

Um elemento-chave dos estudos de Taylor e O'Connell (1985) é o fator " $\rho$ ", que representa a diferença entre o retorno de capital esperado e seu valor presente (“r”). Diferente do que fora proposto por Taylor e O'Connell (1985), a proposta de Chiarella e Di Guilmi (2011) é tornar $\rho$ endógeno, o definindo como uma função das estratégias do mercado de ações. Dito de outra forma, $\rho$ seria uma função da proporção de investidores adotando uma estratégia fundamentalista ou grafista com um choque multiplicador idiossincrático. $\mathrm{O}$ caráter heterogêneo de $\rho$, segundo os autores, implica heterogeneidade nos níveis de investimento das firmas, e como consequência, no seu tamanho e na sua necessidade de buscar recursos financeiros externos.

...the variable $\rho$ plays a key role in the entire story, as it incorporates expectations that emerge in financial markets into the decision process of firms about investment. Taylor and O'Connell(1985) introduce it in order to better isolate the effect of the difference between the anticipated return and the current profit rate, an effect that in the original treatment of Minsky (1975) is directly incorporated in the shadow price Pk. (Chiarella e Di Guilmi, 2011, p.5)

Como o foco central é analisar as transmissões dos choques no setor financeiro para a economia real, o papel de $\rho$ acaba sendo semelhante ao "q de Tobin". Dado o escopo deste trabalho, faz-se impossível explorar todos os pormenores do modelo desenvolvido por Chiarella e Di Guilmi (2011). No entanto, sua contribuição para a evolução de um modelo que apresente aspectos microeconômicos bem fundamentados e considere os pressupostos de Minsky é evidente. Nesse sentido, suas simulações ${ }^{19}$ mostraram-se consistentes com as considerações de Minsky.

...there are boom periods, in which the economy grows at a rate significantly higher than its long run trend. At the same time the availability of credit leads firms to take on more debt. When the units in the worst condition begin to fail the process reverses, causing a depression. This pattern reproduces itself cyclically, revealing a structural fragility of the system. The economy can be stabilised by reducing its capacity 19 Para maiores detalhes ver Chiarella e Di Guilmi (2011), p. 10 
to create endogenous money and the maximum debt ratio allowed. (Chiarella e Di Guilmi, 2011, p.17)

\section{Considerações Finais}

Como sugerido por Weintraub (1977), os fundamentos microeconômicos apropriados para a teoria macroeconômica permanece uma questão em aberto. De forma geral, para alguns pós-keynesianos, como Kregel (1976), os microfundamentos da macroeconomia não podem ser formulados em termos de equilíbrio geral, pois a macroeconomia trataria essencialmente de agregados econômicos e para explicá-los a abordagem econométrica não seria suficiente.

The post-Keynesians prefer, for explana-tions , to let macroeconomics determine the microeconomic pricing mechanism: the long-run relationship between the price level and unit labor costs shapes their view of the microeconomics of price. This survey cannot attempt an evaluation of the post-Keynesian point of view. For such economists who believe that explana-tions for macroeconomic phenomena must be simple, historical, institutional, and based on the behavior of "representative" agents, general equilibrium analysis in any form simply misses the point. (Weintraub, 1977,p.7)

Com o intuito de relativizar tal visão, é preciso observar que, sob a visão de Weintraub (1977), as análises de equilíbrio geral têm ido muito além da tipologia walrasiana, considerando diversos aspectos tais como os custos de informação, a especulação, os ajustes imperfeitos e as estruturas do mercado.

Especificamente, os dilemas provenientes da aproximação entre as esferas micro e macroeconômica da teoria econômica, sob a perspectiva das obras de Hyman Minsky, deixam encalços de uma investigação econômica acalorada e que vem ganhando amplitude. Nesses termos,

The most interesting recent developments in macroeconomic theory seem to me describable as the reincorporation of aggregative problems such as inflation and the business cycle within the general framework of "microeconomic" theory. If these developments succeed, the term 'macroeconomic' will simply disappear from use and the modifier 'micro' will become superfluous. We will simply speak, as did Smith, Ricardo, Marshall and Walras, of economic theory. (Lucas, 1987; p.107-108, apud Aoki e Yoshikawa, 2007; p.2)

A ideia da necessidade de um aparato microeconômico para dar sustentação aos pressupostos e relações causais da teoria minskyana fora defendida exaustivamente. Nesse sentido, a evolução do processo de investigação econômica tem se amparado em construções algébricas, ausentes em sua origem, mas que pouco sentido fariam se fossem limitadas à efêmera matematização. 
A magnitude da contribuição de Minsky para um melhor entendimento da economia capitalista é arrebatadora. Potencialmente abrangente, suas formulações pouco matematizadas em nada impediram sua considerável influência a diversos autore ${ }^{20}$. Dessa forma, distante de transformar as contribuições de Minsky em dogmas irrefutáveis, as construções apresentadas reconhecem sua autoridade sem mitificá-lo, avançando para além de apenas "as did Minsky".

\section{Referências}

Aoki, M. (1996). New Approaches to Macroeconomic Modeling. Cambridge University Press, 1996.

Aoki, M. (2002). Modeling Aggregate Behaviour and Fluctuations in Economics. Cambridge University Press, 2002.

Aoki, M.; Yoshikawa, H. (2007). Non-Self-Averaging in Macroeconomic Models: A Criticism of Modern Micro-founded Macroeconomics, Economics Discussion Papers / Institut für Weltwirtschaft, No. 2007-49, http://hdl.handle. net/10419/17972, 2007.

Arestis, P.; Glickman, M. (1999). Financial crises in south east Ásia: dispelling illusion the minskyan way. UEL, Department of Economics - University of East London, Working Paper 22, December,1999.

Brainard, W.; Tobin, J. (1968). Pitfalls in Financial Model Building. American Economic Review, 58,1968, p. 99-122.

Brainard, W.; Tobin, J. (1977). Pitfalls in Financial Model Building“Asset Markets and the Cost of Capital," in Economic Progress, Private Values, and Public Policy: Essays in Honor of William Fellner, ed. by B.Belassa and R.Nelson, New York: North Holland Publishing Co., 1977

Chiarella, C.; Di Guilmi, C. (2011). The financial instability hypothesis: a stochastic microfoundation framework. Journal of Economic Dynamics \& Control 35, 2011.

Chiarella, C.; Di Guilmi, C. (2012). A reconsideration of the formal Minskyan analysis: microfundations, endogenous money and the public sector. Disponível em: < http://ssrn.com/abstract=1939619>, 2012.

Chick, V. (1983). Macroeconomics after Keynes: a reconsideration of the General Theory. Oxford: Philip Allan, 1983. Trad. Port. Macroeconomia após Keynes: um reexame da Teoria Geral. Rio de Janeiro: Forense Universitária, 1993.

Crotty, J. R.; Goldstein, J.P. (1992). The investment decision of the post Keynesian firm: a suggested microfoundation for Minsky's investment instability thesis. Levy Economic Institute, The. No 79, 1992.

Crotty, J.R. (1990). “Owner-Manager Conflict and Financial Theories of Investment Instability: a Critical Assessment of Keynes, Tobin, and Minsky," Journal of Post Keynesian Economics, 12 (Summer 1990), 1990. p.519-42.

20 Como exemplo, segundo Taylor e O'Connell (1985), pode-se considerar a conhecida obra de Kindlerberger (1978) - Manias, Panics and Crashes - obtêm seu fundamento teórico das ideias de Minsky sobre crises financeiras. 
Fazzari,S.; Ferri,P.; Greenberg,E. (2000). Bounded rationality and Keynes-Minsky fluctuations. August, < http://www.cfeps.org/events/pk2002/confpapers/fazzariferrigreenberg.pdf $>$.

Felix, D. (1999). Open Economy Minsky-Keynes and Global Financial Crises. Apresentado na $9^{\text {a }}$ Hyman P. Minsky Conference on Financial Structure, Jerome Levy Economics Institute, April 21-23, 1999.

Keynes, J. M. The general theory of employment, interest and money. London: Macmillan, 1936.

Kindleberger, C. (2005). Manias Panics and Crashes: A History of Financial Crises, fifth ed. Wiley, 2005.

Kregel, J. Economic Methodology in the Face of Uncertainty, Econ. J.,86 (342), pp.209-25, Jun, 1976.

Kregel, J. (1998). Yes, 'it' did happen again: a Minsky crisis happened in Asia. Jerome Levy Institute, 1998. (Working Paper, n. 235).

Lourenço, A. (2006). O pensamento de Hyman P. Minsky:alterações de percurso e atualidade. Economia e Sociedade, Campinas, v. 15, n. 3, dez. 2006.

Lucas, R.E. Models of Business Cycles, New York: Blackwell, 1987.

Minsky, H.P. (2008). John Maynard Keynes. Columbia University Press, New York, 1975. Ed, 2008.

Minsky, H. (1982a) Central Banking and Money Market Changes, in Quarterly Journal of Economics, n. 71, 1957a, maio. Reimpresso em Minsky, H. Can It Happen Again ? Essays on Instability and Finance. Nova York: M. E. Sharp, 1982a.

Minsky, H.P. (1982). Can it happen again? In: CARSO, E. (Org.). Banking and monetary studies. Homewood: R.D. Irwin, 1963. Reimpresso em Minsky,1982.

Minsky, H.P. (1986). Stabilizing an Unstable Economy, New Haven: Yale University Press, 1986.

Minsky, H.P. (1994). Integração financeira e política monetária. Economia e Sociedade, Campinas, n. 3, dez. 1994.

Palley, T. I. (1999). The stock market and investment: another look at the microfoundations of "q" theory. Forthcoming Cambridge Journal of Economics, 1999.

Pech, W.; Milan, M. (2009). Behavioral economics and the economics of Keynes. The Journal of Socio-Economics 38, 2009. 891-902p.

Summa, R. F. (2005). Um modelo dinâmico de fragilidade financeira para economia aberta. VIII Encontro de Economia da Região Sul. Anpec Sul, 2005.

Taylor, L.; O'Connell, S.A. (1985). A Minsky crisis. The Quarterly Journal of Economics 100, 1985. 871-885p.

Toporowski, J. (2006). Methodology and Microeconomics in the Early Work of Hyman P. Minsky. Working paper 480, The Levy Economics Institute Working Paper Collection, 2006.

Weintraub, E.R. (1977). The microfoundations of Macroeconomics: a critical survey. Journal of Economic Literature, vol. 15, N.1, Mar, 1977, p 1-23. DIsponível em: http://www.jstor.org/stable/2722711 . 